\title{
CLINICAL PROFILE AND COLONOSCOPIC FINDINGS IN PATIENTS PRESENTED WITH LOWER GASTROINTESTINAL BLEEDING IN UCMS
}

\author{
Aakash Shahi, ${ }^{1}$ Suresh Shrestha, ${ }^{2}$ Shatdal Chaudhary, ${ }^{1}$ Pushpa Raj Dhakal, ${ }^{1}$ Anita Shah ${ }^{3}$
}

\begin{abstract}
\section{INTRODUCTION}

The lower gastrointestinal bleeding (LGIB) is an alarming symptom and common disease with annual admission of $0.15 \%$ with mortality rate of $5-10 \%$. LGIB is caused by neoplastic and non-neoplastic lesions. For accurate diagnosis of various colorectal lesions, colonoscopy is gold standard, convenient and cost effective procedure. It is the investigation of choice in LGIB and helps in early diagnosis of colorectal carcinoma. This study was aimed to scrutinize the clinical and colonoscopic findings in patients with LGIB in Universal College of Medical Sciences-Teaching Hospital (UCMS-TH).
\end{abstract}

\section{MATERIAL AND METHODS}

This was a hospital based prospective observational study conducted after taking permission from institutional review committee in January 2017 at UCMS-TH from 15 January 2017 to 15 January 2018. All patients presenting with LGIB who fulfilled inclusion and exclusion criteria and gave written consent were included.

\section{RESULTS}

Total 88 patients were included in the study. The mean age of our patients was $48 \pm 17$ years with age range from $17-81$ years. Majority were in the age group 50-60 years $(25 \%)(n=22)$. Colonoscopy detected abnormality in $73.8 \%$ cases. The common non-neoplastic were haemorrhoids and non-specific colitis (14.5\% each) followed by $12.5 \%$ of neoplastic cases. The higher frequency of colorectal lesions was observed in males comprising $72.7 \%(\mathrm{n}=64)$ patients. The most commonly diagnosed etiologies of LGIB were haemorrhoid and nonspecific colitis respectively.

\section{CONCLUSION}

Colonoscopy detected abnormality in $75 \%$ of cases. The common causes of LGIB were haemorrhoids and non-specific colitis followed by neoplastic lesion. A careful history, physical and colonoscopic examination with or without biopsy makes significant impact for early diagnosis and treatment.

\section{KEYWORDS}

Colonoscopy, Haemorrhoids, Lower GI bleeding.

1. Department of Internal Medicine, Universal college of Medical Sciences Teaching Hospital, Bhairahawa, Nepal

2. Department of Internal Medicine, Dev Hospital, Chitwan, Nepal

3. Department of Pathology, Universal College of Medical Sciences Teaching Hospital, Bhairahawa, Nepal

DOI: http//doi.org/10.3126/jucms.v9i01.37859

\author{
For Correspondence \\ Dr. Aakash Shahi \\ Department of Internal Medicine \\ Universal College of Medical Sciences \\ Bhairahawa, Nepal \\ Email:aakashshahi1983@gmail.com
}




\section{INTRODUCTION}

Gastrointestinal (GI) bleeding is a frequent cause of hospital admission and is a common factor for hospital morbidity and mortality. The annual hospital admission rate in the United States and United Kingdom is estimated to be around 150 patients per 100,000 populations with a mortality rate of $5 \%$ $10 \%$.

Depending upon site, GI bleeding is divided into upper and lower GI bleeding. ${ }^{2}$ A lower Gastrointestinal bleed (LGIB) is defined as bleeding that occurs from GI tract, distal to the ligament of Treitz.

Bleeding from the lower gastrointestinal tract may account for up to $20-25 \%$ of all acute GI bleeding. ${ }^{4}$ Although $80-85 \%$ of patients have a self-limiting acute LGIB and an uncomplicated hospitalization, the reported mortality rate ranges from $2 \%$ to $4 \%{ }^{5}$. The annual incidence of LGIB is $0.03 \%$ and it increases 200 -fold from the second to eighth decades of life. ${ }^{6}$

The etiology and the epidemiology of LGIB varies according to the environmental conditions depending upon the life style, dietary habits, prevalence of smoking, history of drug intake, age, longevity of the population etc. Most of the data suggests that colonic diverticula are the most frequent source of LGIB followed by angiodysplasia, colitis (ischemic, infectious, chronic inflammatory bowel disease), neoplasm, small bowel bleeding and post-polypectomy bleeding. However, in the Indian experience, the etiology differs significantly in which nonspecific ulcers account for $30 \%$ of cases while the rest are enteric ulcers $15 \%$, tubercular ulcers $6 \%$, neoplasm $6 \%$, amoebic ulcers $6 \%$, angiodysplasia $6 \%$ and others. ${ }^{7}$ It requires complete history, physical examination, including a digital rectal examination and different investigations including colonoscopy to find out the causes of lower GI bleeding. ${ }^{8}$

Colonoscopy is a safe and effective diagnostic procedure in patients with lower GI bleeding. With the advent of the colonoscopic era, the diagnosis and management of colonic disorders took a quantum leap forward. ${ }^{8}$ Colonoscopy is generally safe, accurate and well tolerated, gold standard technique in diagnosing colonic pathology and treatment of colonic disorders. It enables visual inspection of the entire large bowel from the distal rectum to the caecum. Hence this study was done to find out the clinical profile, identify etiology of LGIB and the usefulness of colonoscopy to find out its etiology.

\section{MATERIAL AND METHODS}

The permission to conduct research was taken from the institutional review committee (IRC) of Universal College of Medical Sciences, Teaching Hospital (UCMS-TH), Bhairahawa, Nepal. It was a single centered, cross sectional, hospital based observational study from 15 January 2017 to 15 January 2018. All the patients scheduled for colonoscopy at
Endoscopy unit of UCMS-TH during the study period were included and total of 88 patients were subjected in this study after taking informed consent from the patient or the patient relatives.

\section{Inclusion criteria}

All patients presented with LGIB at endoscopy unit, aged more than 16 years and who gave written consent.

\section{Exclusion criteria}

Patients with suspected upper source of GI bleeding and acute infectious diarrhea.

Patients aged less than 16 years.

Patients unfit for colonoscopy or hemodynamically unstable (e.g. severe shock, recent myocardial infarction, unstable angina, cardiac arrhythmia, severe respiratory disease, possible visceral perforation, uncooperative patients, unconscious patient).

- Patients who didn't give written consent.

All patients who fulfilled inclusion and exclusion criteria were included. After enrollment in the study, demographic detail, full history, presenting features of lower GI bleeding and colonoscopic findings were recorded.

All the patients were instructed to take the 2-day split bowel preparatory regime of polyethylene glycol given 8 hours prior to procedure and patient kept on liquid diet from 24 hours prior to procedure, whenever possible.

All patients underwent colonoscopic examination which was done by means of colonoscope of Fujinon EVE Processor EPX-201H processor and Fujinon EC-250WL5 endoscope following standard high level disinfection by $2.5 \%$ glutaraldehyde. Colonoscopic findings and abnormalities were noted. Biopsy was taken from the suspected lesions and sample was transferred to a container with $10 \%$ neutral formalin using non-toothed forceps, properly labelled and sent to the Department of Pathology.

The data was recorded in proforma and was entered in the windows office version 10, excel spread sheet and transferred to SPSS version 20 and statistical analysis was done. Categorical data were expressed as corresponding percentage.

\section{RESULTS}

All the patients fulfilling inclusion and exclusion criteria attending emergency department or inpatients who developed acute lower gastrointestinal bleeding after admission for other causes in UCMS-TH were included in this study. Total 88 patients analyzed systematically for the study. In the current study, the majority of patients $25 \%(n=22)$ were in the age group of 50-60 years and mean age of study patient was 48 years \pm 17 years ranging from minimum of years 17 to maximum of 81 years. The male to female ratio was $2.7: 1$ (Table 1). 
Table 1. Distribution of study patients according to age groups and gender

\begin{tabular}{lcccc}
\cline { 1 - 3 } Age group (years) & Male n (\%) & Female n (\%) & Total n (\%) \\
\hline$<40$ & $25(28.41)$ & $07(7.96 \%)$ & $32(36.37)$ \\
$40-59$ & $17(19.32)$ & $07(7.96 \%)$ & $24(27.28)$ \\
$\geq 60$ & $22(25)$ & $10(11.37)$ & $32(36.37)$ \\
\hline Total & $64(72.73)$ & $24(27.28)$ & $88(100)$ \\
\hline
\end{tabular}

Among 88 patients enrolled in the study, bleeding per rectum was present in $100 \%(\mathrm{n}=88)$ cases. Most of the patients had various symptoms associated with per rectal bleeding. The other symptoms during presentation were constipation $>$ loose stool $>$ abdominal pain $>$ weight loss in $29(32.96 \%), 28$ $(31.82 \%), 21(23.87 \%), 5(5.69 \%)$ patients respectively. So in our study patients, the least common associated symptom was weight loss.

In present study, different comorbidities including hypertension in $14(15.9 \%)$, diabetes mellitus in $7(8 \%)$ along with personal history of active smoking in $22(25 \%)$, chronic alcohol consumption in $18(11.37 \%)$, non-vegetarian diet in $78(73.87 \%)$ and recent consumption of drugs like NSAIDS, antiplatelet drugs and anticoagulant was observed in $7(8 \%)$ patients.

Pallor was the most common clinical finding in $55(62.5 \%)$ patients under study.

All the study patients were investigated for haemoglobin level and subcategorized into anaemic and non-anaemic patients. The presence of anaemia was noted in $55(62.5 \%)$ patients and remaining $37.5 \%(\mathrm{n}=30)$ patients had normal haemoglobin (Table 2).

Table 2. Distribution of study patients according to haemoglobin level

\begin{tabular}{lcccc}
\hline Anemia & \multicolumn{2}{c}{ Sex } & Total & $p$-value \\
& F & M & N $(\%)$ & \\
\hline Normal & 11 & 22 & $33(37.50)$ & $<0.01$ \\
Mild & 3 & 21 & $24(27.27)$ & \\
Moderate & 7 & 19 & $26(29.55)$ & \\
Severe & 3 & 2 & $5(5.68)$ & \\
\hline Total & 24 & 64 & $88(100)$ &
\end{tabular}

Complete colonoscopy with visualization of terminal ileum was performed in all patients and site of the lesion was noted (Table 3).

Table 3. Distribution of the study population according to site of lesion

\begin{tabular}{lc}
\hline \multicolumn{1}{c}{ Site } & Frequency $\mathrm{n}(\%)$ \\
\hline Anal canal and rectum & $56(63.64)$ \\
Sigmoid colon & $22(25)$ \\
Descending colon & $12(13.64)$ \\
Splenic flexure & $4(4.55)$ \\
Transverse colon & $2(2.28)$ \\
Hepatic flexure & $1(1.14)$ \\
Ascending colon & $3(3.42)$ \\
Ileum & $1(1.14)$
\end{tabular}

The common abnormal colonoscopic finding was haemorrhoids $(14.70 \%)$, growth $(13.63 \%)$ and anal fissure $(11.3 \%)$. Etiology of bleed was not identified in thirty (26.33\%) patients as their colonoscopy was normal (Figure 1).

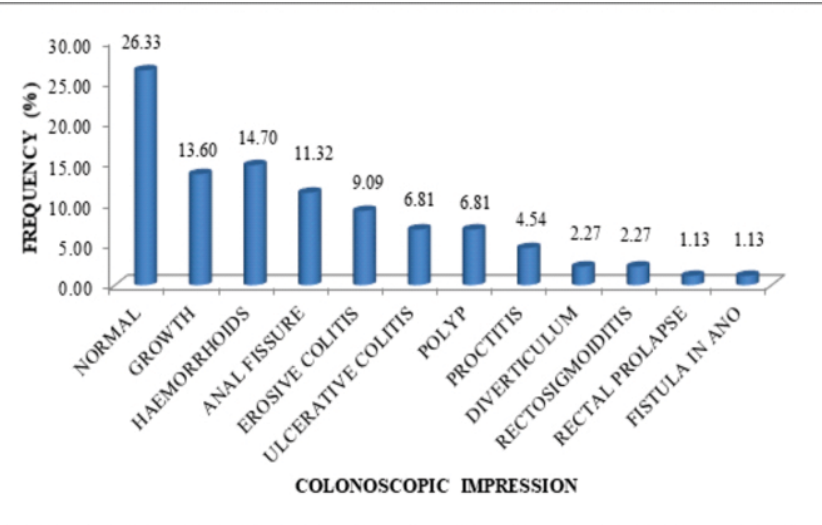

Figure 1. Distribution of study patients according to colonoscopic impression

Out of 88 patients included in the study, biopsy was performed in $46.59 \%(n=41)$ cases. Histopathology reports in these cases were recorded. In this study, non-specific colitis was the most common diagnosis in histopathology comprising $31.7 \%$ $(n=13)$ cases, followed by focal active colitis $24.4 \%(n=10)$ cases and high grade dysplasia $14.7 \%(n=6)$.

The most common etiology for lower GI bleed after colonoscopy and histology were haemorrhoids and nonspecific colitis in $13(14.77 \%)$ patients in each followed by malignancy in $11(12.5 \%)$ patients. The final diagnosis was considered as the etiological lesion for lower GI bleeding (Figure 2).

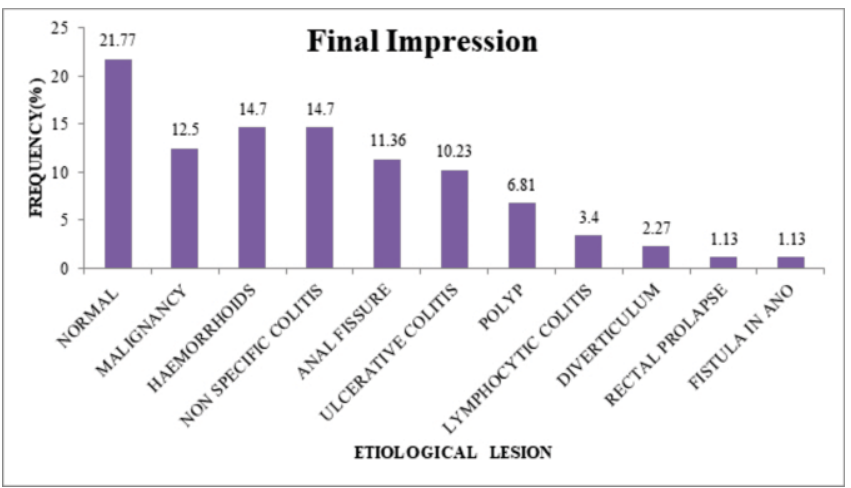

Figure 2. Distribution of the study patients according to final diagnosis

Out of total 88 study patients enrolled in our study, $21.5 \%$ $(n=19)$ patients were normal and rest $78.40 \%(n=69)$ patients had significant findings. In the age group 51-60 years, haemorrhoids were most common etiology of LGIB followed by anal fissure. Ulcerative colitis had bimodal distribution. It 
was common in the age group $<30$ years and $51-60$ years. Malignancy was most common in the older age $>60$ years. Non-specific colitis was more or less common in all age group (Table 4).

Table 4. Cross tabulation of final diagnosis with different age group

\begin{tabular}{lcccccc}
\hline \multicolumn{1}{c}{ Categories } & \multicolumn{7}{c}{ Age category (in years) } & Total \\
\hline Final impression & $<30$ & $31-40$ & $41-50$ & $51-60$ & Above 60 & \\
Normal & 8 & 2 & 4 & 1 & 4 & 19 \\
Anal fissure & 0 & 2 & 2 & 4 & 2 & 10 \\
Polyp & 1 & 1 & 2 & 1 & 1 & 06 \\
Malignancy & 1 & 2 & 0 & 3 & 5 & 11 \\
Non-specific colitis & 3 & 3 & 2 & 3 & 2 & 13 \\
Haemorrhoids & 2 & 2 & 1 & 5 & 3 & 13 \\
Diverticulum & 0 & 0 & 0 & 0 & 2 & 02 \\
Lymphocytic colitis & 1 & 1 & 0 & 0 & 1 & 03 \\
Rectal prolapse & 0 & 0 & 0 & 1 & 0 & 01 \\
Ulcerative colitis & 3 & 0 & 1 & 4 & 1 & 09 \\
Fistulo in ano & 1 & 0 & 0 & 0 & 0 & 01 \\
Total & 20 & 13 & 12 & 22 & 21 & 88 \\
\hline
\end{tabular}

\section{DISCUSSION}

Lower gastrointestinal bleeding is a common reason for hospital admission and a major cause of morbidity and mortality worldwide and is so in developing country like Nepal. The clinical profile including age, gender, alcohol consumption and co-existing comorbidities, clinical features and colonoscopic features of the patients with this condition were studied and correlated.

The mean age of the study patient was 48 years with standard deviation of \pm 17 years ranging from minimum 17 years to maximum of 81 years. Similar finding was observed in a study done by Chaudhary et al with mean age of 45.23 years. Likewise it was 47.10 years in a study conducted by Bafandeh Y, et al. ${ }^{10}$

In our study, the incidence of lower GI bleeding increased with increasing age i.e.14.78\% $(n=13)$ in the age group of $30-40$ years to $25 \%(n=22)$ in the age group of $50-60$ years. One of the reason for the increased incidence of lower GI bleeding with increasing age could be as a result of the gastrointestinal diseases specific to the increasing age like haemorrhoids, ulcerative colitis and colorectal carcinoma. ${ }^{8,11}$ The other reasons are due to increased prevalence of comorbid conditions such as cardiovascular diseases, renal diseases and diabetes mellitus in old age, as well as increased use of drugs like anticoagulants and NSAIDs by the elderly people, which increase the risk of LGIB. ${ }^{12}$ In present study, LGIB was more prevalent among males as $72.7 \%$ of the patients were males and male to female ratio was $2.66: 1$ in concordance to present study, Chaudhary et al, Alruzug I et al and Badiger R et al reported similar male predominance..$^{13-15}$ In other parts of Nepal also, male predominance was reported by Chaudhary $S$ et al. ${ }^{9}$ Along with the complain of bleeding per rectum in present study, altered bowel habit, mainly constipation was the most common symptom of patients $(n=29)$ followed by loose stool (28), pain abdomen $(n=21)$ and weight loss $(n=5)$ was observed. This finding was consistent with the study done by Adelstein $\mathrm{B}$ et al. ${ }^{16}$ In contrary, the commonest clinical symptom was hematochezia $(80 \%)$, followed by constipation $(76 \%)$, loss of weight $(56 \%)$ and blood mixed with stools $(50 \%){ }^{15}$

It was observed in our study that the comorbidities present were diabetes and hypertension. Majority of patients had no history of diabetes $(92 \%)$. Similar observation was made by study carried out in Nigeria. ${ }^{17}$ In the present study, $20.5 \%$ of the study patients were alcohol consumer thus showing no any attribution to lower GI bleeding and personal history of smoking was noted in $22 \%$ of patients.

The most common finding on colonoscopy in our study was haemorrhoids. This is similar to the findings of Akere A et al and Olokoba A et al. ${ }^{17,18}$ Also similar study conducted in UK, found haemorrhoids as the commonest etiology of lower GI bleeding. ${ }^{19}$ Majority of our patients with the diagnosis of haemorrhoids were less than 60 years of age. However, diverticulosis (18.5\%), IBD (19.3\%) and polyps (25.1\%) were the common colonoscopic findings in a study of Sousa et al. ${ }^{20}$ This indicates that the prevalence of lesions varies according to the geographic location.

Most of the lesions were located in anal canal and rectum then in sigmoid colon. This is similar to the study done by Joukar F et al where site of involvement was anal canal (43.8\%) and rectosigmoid $(26 \%){ }^{21}$

Most of the carcinoma occurred in the older age group more than 50 years of age and predominantly located in the rectum. In the study done by Joukar et al observed most of the malignancy occurred in the age group of $60-80$ years $(43.1 \%)$ followed by age group of $20-40$ years $(20.8 \%)$ and $40-60$ years $(16.7 \%)^{21}$

According to this study, on colonoscopic appearance of lesions and histological examination, non-neoplastic lesions comprised of $65.90 \%(n=58)$ of all the diagnosed cases and neoplastic lesions comprised of $12.50 \%(n=11)$. Similar findings were observed in a study of Rajbhandari et al in which non-neoplastic lesions comprised of $73.9 \%{ }^{22}$ However a study by Teague et al found neoplastic lesions as the common finding than the non-neoplastic lesions. ${ }^{23}$

Colonoscopy is simple, accurate and well tolerated technique recommended as a first line investigation in patients with LGIB who are hemodynamically stable.

\section{CONCLUSION}

In present study, we have shown the clinical profile of patients who presented with LGIB. The mean age of the study patients was 48 years with male to female ratio of $2.66: 1$. Along with the complain of bleeding per rectum, altered bowel habit, 
mainly constipation was the most common symptoms of patients. Colonoscopy detected abnormality in $73.8 \%$ cases out of which $60.23 \%$ cases were non-neoplastic and $12.5 \%$ cases were neoplastic. The common non-neoplastic causes of lower GI bleeding were haemorrhoids and non-specific colitis (14.5\% each) followed by neoplastic lesion constituting of $12.5 \%$ of cases of malignancy. Rectum was the most common site for both neoplastic and non-neoplastic lesions. A careful clinical history, physical examination with colonoscopic visualization of the lesion with or without biopsy makes the significant impact to the early diagnosis and guides for proper treatment of the patients.

Colonoscopy is powerful tool in detecting the etiology of lower GI bleeding and aids to find out the site, characteristics and nature of lesion with or without colonoscopic directed biopsy. Thus there is a need for understanding the knowledge about the clinical profile and role of colonoscopy in patients presented with lower GI bleeding.

\section{CONFLICT OF INTEREST}

None

\section{REFERENCES}

1. Hilsden RJ, Shaffer EA. Management of gastrointestinal hemorrhage. Can Fam Physician. 1995 Nov;41:1931-6, 1939-41.

2. Kim BSM. Diagnosis of gastrointestinal bleeding: A practical guide for clinicians. World J Gastrointest Pathophysiol. 2014;5(4):467.

3. Vernava AM, Moore BA, Longo WE, Johnson FE. Lower gastrointestinal bleeding. Dis Colon Rectum. 1997 Jul;40 (7):846-58.

4. Jensen DM, Machicado GA. Diagnosis and treatment of severe hematochezia: The role of urgent colonoscopy after purge. Gastroenterology. 1988;95(6):1569-74.

5. Robins J, Shrestha A, Hampton J, Shrestha BM. Management of acute lower gastrointestinal bleeding: principles and current practice in the United Kingdom. J Nepal Med Assoc. 2015;53(200):304-10.

6. ASGE Standards of Practice Committee, Pasha SF, Shergill A, Acosta RD, Chandrasekhara V, Chathadi KV, Early D, et al. The role of endoscopy in the patient with lower GI bleeding. Gastrointest Endosc. 2014;79(6):875-85.

7. Dar I, Dar W, Khan M, Kasana B, Sofi N, Hussain M, et al. Etiology, clinical presentation, diagnosis and management of lower gastrointestinal bleed in a Tertiary Care Hospital in India: A retro-prospective study. J Dig Endosc. 2015;6(3):101-9.

8. Jehangiri AU, Gul R, Hadayat R, Khan AN, Zabiullah, Khursheed L. Causes of lower gastrointestinal bleeding on colonoscopy. J Ayub Med Coll Abbottabad. 2017 JulSep;29(3):468-471.
9. Chaudhary S, Chaudhary P, Jaiswal N, Chaurasia R. Colonoscopy: A two year experience from Western Nepal. J Univers Coll Med Sci. 2013;1(3):28-32

10. Bafandeh Y, Yazdanpanah F. Distribution pattern of colorectal diseases based on 2300 total colonoscopies. Gastroenterol Hepatol Bed Bench. 2017;10(2):90-6.

11. Zia N, Hussain T, Salamat A, Mirza S, Hassan F, Waqar A. Diagnostic evaluation of patients presenting with bleeding per rectum by colonoscopy. J Ayub Med Coll Abbottabad. 2008;20(1):73-6.

12. Chait MM, Rey JF. Lower gastrointestinal bleeding in the elderly. World J Gastrointest Endosc. 2010;2(5):147-54.

13. Chaudhary V, Hyser MJ, Gracias VH, Gau FC. Colonoscopy: the initial test for acute lower gastrointestinal bleed. Am Surg. $1984 ; 64(8): 723-28$.

14. Alruzug IM, Aldarsouny TA, Semaan T, Almustafa A. lower gastrointestinal bleeding in Saudi patients. A Retrospective Longitudinal Study. J Gastrointest Dig Syst. 2016;6(2):2-5.

15. Badiger RH, Hajare S, Kantamaneni R, Kole A. Etiological profile of patients presenting with lower gastrointestinal bleeding at tertiary care hospital at Belagavi: a cross sectional study. Int J Adv Med. 2017;4(5):1429-33.

16. Adelstein B, Irwig L, Macaskill P, Turner RM, Chan SF, Katelaris PH. Alimentary Pharmacology and therapeutics who needs colonoscopy to identify colorectal cancer? Bowel symptoms do not add substantially to age and other medical history. Aliment Pharmacol Ther. 2010;32:270-281.

17. Akere A, Oke TO, Fakoya TO. Colonoscopic findings in patients presenting with lower gastrointestinal bleeding at the University College Hospital, Ibadan, Nigeria. Nigerian Journal of Gastroenterology and Hepatology. 2017;9(1):7-13.

18. Olokoba AB, Obateru OA, Bojuwoye MO, Olatoke SA, Bolarinwa OA, Olokoba LB. Indications and findings at colonoscopy in Ilorin, Nigeria. Niger Med J. 2013;54(2):111-4.

19. Metcalf J V, Smith J, Jones R, Record CO. Incidence and causes of rectal bleeding in general practice as detected by colonoscopy. Br J Gen Pract. 1996;46(404):161-4.

20. Sousa JB de, Silva SME, Fernandes MB de L, Nobrega AC dos S, Almeida RM de, Oliveira PG de. Colonoscopies performed by resident physicians in a University Teaching Hospital: a consecutive analysis of 1000 cases. Arq Bras Cir Dig. 2012;25 (1):9-12.

21. Joukar F, Majd SK, Fani A, Nazari N, Mansour-Ghanaei F. Colonoscopy outcome in North of Iran (Guilan): 2006-2009. Int J Clin Exp Med. 2012;5(4):321-5.

22. Rajbhandari M, Karmacharya A, Khanal K, Dhakal P, Shrestha R. Histomorphological profile of colonoscopic biopsies and pattern of colorectal carcinoma in Kavre district. Kathmandu Univ Med J. 2013;11(43):196-200.

23. Teague RH, Salmon PR, Read AE. Fibreoptic examination of the colon: a review of 255 cases. Gut. 1973;14(2):139-42. 